\title{
A modelling framework for assessing the economic impact of climate change in the Caribbean
}

\author{
Roberto Roson
}

ABSTRACT

The ECLAC-Climate Impacts Assessment Model (CIAM) is a modelling platform that has been created to assess the economic consequences of climate change in the Caribbean. The model can be freely accessed, downloaded and even modified. The version available is a full-fledged model which can readily be used to conduct simulation exercises. This paper provides a general description of the model and an illustrative simulation exercise. Our results from this exercise highlight the fact that the Caribbean is a highly vulnerable region where climate change is expected to generate sizeable and negative economic consequences. Research Director at the Centre for Research on Energy and Environmental Economics and Policy (IEFE) at Bocconi University in Milan, Italy. roson@unive.it 


\section{I}

\section{Introduction}

Climate change is a very complex phenomenon. Largescale computer models are run to simulate future climate conditions under different scenarios and assumptions. Socioeconomic models are used to assess climate change impacts and the costs and benefits of mitigation and adaptation policies. Physical and social models are often integrated into complex integrated assessment models (IAMs).

A consistent finding among the many and diverse impact analyses is that the negative consequences of climate change will be felt primarily in the developing countries of Latin America and the Caribbean, Africa and Asia. This poses a problem of equity in international negotiations, like those of the United Nations Framework Convention on Climate Change, as developing countries are historically responsible for only a negligible share of global greenhouse gas emissions. Quantitative models can greatly help in identifying the burdens and benefits of global climate policies.

Unfortunately, the most vulnerable regions are also those where a rigorous assessment analysis is rendered difficult by lack of data and expertise. In the Caribbean, for example, no tool for assessing the social impacts of climate change has been available for a long time. More generally, there is a lack of quantitative socioeconomic models focusing on the Caribbean subregion. The use of simulation, optimization, econometric and forecasting models is not widespread in the area, even in institutions like the national central banks (with only a few notable exceptions, e.g., Jamaica). Not surprisingly, the databases necessary to support and implement applied models are lacking or inadequate. Policymakers are usually unaware of the existence of quantitative economic models and decision support systems.

This issue has been recently tackled by the ECLAC subregional headquarters for the Caribbean, with financial support from the Australian Agency for International Development (AusAid). ECLAC has commissioned a study to either develop a prototype model or modify an existing framework that will address climate change impacts in the Caribbean in a modelling framework. This paper provides a general description of the model created for this purpose, the ECLAC-Climate Impacts Assessment Model (CIAM), and an illustrative simulation exercise.

ECLAC-CIAM has been designed and developed on the basis of some fundamental concepts. First, a systemic approach has been followed. A systemic approach to modelling climate impacts is essential because climate change is a global phenomenon and the world economy is globalized. The economic effects of climate change in the Caribbean may be driven by physical impacts occurring in the United States, say, much more than by direct physical impacts in the Caribbean. However, most existing sectoral studies fail to capture these systemic relationships.

Second, we needed the model to be able to consider multiple impact effects simultaneously. This is necessary because climate change generates economic consequences in a variety of sectors and in different ways. In addition to sea-level rise, mention could be made of the effects on agricultural productivity (due to changing precipitation, increased evapotranspiration and carbon fertilization), on tourism demand (changing incomes, prices and tourism attractiveness), on energy demand (increased demand for cooling, decreased demand for heating), on human health and labour productivity (variations in mortality and morbidity), and so on. From a policy perspective, the simultaneous assessment of multiple impacts is necessary because: (1) there is often a need to evaluate the overall effect of climate change on a particular country or region; (2) knowing the contribution of each sectoral effect to the total may help in determining priorities for adaptation policies, and (3) different impacts may have counteracting effects.

Third, the model has been designed with a modular structure that can easily be accessed and understood by other researchers. In order to keep up with progress in the field of climate science, new elements can be easily inserted in the future, possibly by Caribbean researchers. Indeed, we hope to generate a "multiplier effect", with ECLAC-CIAM acting as a seedbed for further research and model development.

A major difficulty of simulating with complex mathematical models is that it can require specific, expensive software that scientists from developing countries may be unable to afford. We tried to circumvent this obstacle by basing ECLAC-CIAM only on auxiliary programs that can be downloaded and used free of charge. The program codes, all data and parameters, documentation and links to auxiliary software can be found and downloaded for free at: http://venus.unive.it/roson/ciam.html. 
This paper is organized as follows. Section II provides a concise state-of-the-art review of the numerical models available for assessing the socioeconomic impacts of climate change. Section III describes the structure and operational functioning of ECLAC-CIAM. Section IV illustrates a simulation exercise which analyses the economic impacts of climate change in the year 2050. Section V concludes.

\section{II}

\section{The state of the art}

\section{Applied economic models for climate change assessment}

Several applied numerical models have been developed to assess the economic impact of climate change and related policies. These models differ in their scope, methodology, level of aggregation, treatment of technology and uncertainty, and degree of integration with climate models.

A first distinction can be drawn between simulation (positive) and optimization (normative) models. Simulation models are used to conduct "what if" experiments, by considering variations in climate or policy (or both). Almost all models with a computable general equilibrium (CGE) core, including ECLAC-CIAM presented here, are simulation models. Other models in this class are DART (Springer, 1998), ENVISAGE (Roson and van der Mensbrugghe, 2012), EPPA (Paltsev and others, 2005), GEMINI-E3 (Bernard and Vielle, 2008), GREEN (Burniaux and others, 1992; Lee and others, 1994), GTAP-E (Burniaux and Troung, 2002), GTEM (Pant, 2007) and ICES (Eboli, Parrado and Roson, 2010). Optimization models instead take a target, in the form of a function to be maximized or minimized. All models based on intertemporal utility maximization "à la Ramsey" fall into this class. Perhaps the most popular group of models of this kind is the Dice/Rice family, developed by William Nordhaus (Nordhaus, 1994; Nordhaus and Yang, 1996). Other models are EDGE (Jensen and Thelle, 2001), ENTICE (Popp, 2003), FUnd (Anthoff and Tol, 2008), MERGE (Manne, Mendelsohn and Richels, 1995), PaGe (Hope and others, 1993), WIAGEM (Kemfert, 2001) and WITCH (Bosetti and others, 2006).

Simulation models are usually large-scale, regionally and industrially detailed models. From a mathematical point of view, they are large nonlinear systems of equations, to be solved with general mathematical packages or specialized software (e.g., GEMPACK, PATH/GAMS). Optimization models, on the other hand, are typically very aggregated models, solved by means of non-linear programming algorithms (e.g., MINOS/GAMS, CONOPT/GAMS). The Rice/Dice models, for example, simply consider one aggregate good that can be used for either consumption or investment. Climate change impacts are also modelled in a rather crude way, using a single damage function, with the level of potential income falling as temperatures increase.

The various approaches differ in terms of integration with climate models. Some approaches are "soft-linked" with climate models. This means that a climate model (e.g., a global circulation model) is first used to generate a climate scenario, which is taken as given within the economic model. Results from the latter can then be fed into the climate scenario, in an iterative process. Other models are "hard-linked", meaning that they possess a climate module which is fully integrated into the system. Most optimization models have this feature, but so do some large-scale simulation models, like EPPA and ENVISAGE. The advantage of having mutually consistent economic and climate blocks inside the same model should be balanced against the loss of complexity in the climate component, which is usually a reducedform general circulation model including only a limited number of equations.

When models consider the distant future, changes in available technology should be taken into account. Again, investment in green technologies could be fostered by economic incentives, possibly as part of a climate policy package. A few models (e.g., WITCH, ENTICE) explicitly address the issue of "endogenous technical change". However, estimation of model parameters is very difficult, being somewhat arbitrary and subjective. Other models consider the existence of "backstop technologies". These are technologies which are available today but are too costly to be viable under present economic conditions. Nonetheless, they may put an upper bound on the cost of more traditional technologies, like those based on 
fossil fuels, which could become much more expensive in the future.

A special problem is associated with intertemporal optimization models, like Rice/Dice and PAGE. These models require the use of discount factors, which cannot be easily estimated from current interest rates when the optimization horizon is far into the future and investment returns are affected by several uncertainties. Especially since the publication of The Economics of Climate Change: The Stern Review (Stern, 2007), there has been a vigorous debate stressing how sensitive results from these models are to assumptions about discount factors. Furthermore, there is no single, correct scientific methodology that should be followed in the estimation process, because assumptions about discount factors are affected by (sometimes hidden) subjective value judgments.

\section{Advantages and limitations of CGE models for climate change impact assessment}

ECLAC-CIAM is a CGE model based on the GTAP formulation and extended to include a set of sectoral damage functions. As such, it shares all the advantages and disadvantages of other general equilibrium models in the field, which are associated with the key characteristics briefly summarized above.

On the positive side, the high level of disaggregation makes it possible to understand the complex structural interdependencies of globalized economic systems, and furthermore opens the way to a precise delineation of climate change impacts on a finely detailed industrial and geographical scale. Since CGE models are generalpurpose tools not originally designed for climate change analysis, it is easy to assess how non-climate policies may affect the climate, and vice versa. The rich output of the simulation exercises can be further processed (as it is, indeed, in ECLAC-CIAM). For example, the exchange of "virtual carbon" can be estimated from the origin/ destination matrices of trade flows (Atkinson and others, 2010), which is very useful information in the context of international climate negotiations.
On the negative side, CGE models are highly data-demanding, having been originally conceived for short-run policy analysis. Their use over a much longer time horizon may be problematic if significant changes in technology or consumer preferences substantially alter the economic structure from its current state. For this reason alone, they should not be regarded as forecasting tools or used to construct future economic scenarios.

\section{Climate change assessment in the Caribbean}

Basically, all recent studies on climate change effects in the Caribbean have been conducted with support from and under the auspices of ECLAC, often in association with other international bodies. The most recent publication is The Economics of Climate Change in the Caribbean. Summary Report 2011 (ECLAC, 2011). Further research findings have been presented at international workshops, but not published as yet.

The 2011 summary report presents the results of climate change scenarios for the Caribbean, obtained with the use of a regional circulation model driven by two general circulation models (ECHAM4 and HADCM3). The model predicts an increase in average temperature by 2050 , relative to the $1960-1990$ baseline, of $1.78^{\circ} \mathrm{C}$ for the region as a whole under scenario A2 of the Intergovernmental Panel for Climate Change (IPCC) Special Report Emissions Scenarios (SRES) (IPCC, 2000) and $1.84^{\circ} \mathrm{C}$ under scenario B2 of the SRES. The picture for precipitation is mixed, with increases in some countries and decreases in others. It was also found that some increase in tropical cyclone intensity would be likely if the climate continued to warm.

The report includes a number of sectoral impact studies, namely those for agriculture, the coastal and marine environment, human health, tourism, transportation, water resources, and energy. These studies are hardly comparable, but nonetheless have the merit of focusing on the Caribbean, highlighting difficulties and challenges in the estimation of physical climate change impacts for the region. 


\section{III}

\section{Model structure}

\section{Overview}

ECLAC-CIAM includes three modules, operating sequentially, as shown in figure 1.

The first module is used to translate values for climate variables into changes in economic parameters for the global macroeconomic component. The CGE module is then used to conduct a comparative static simulation, contrasting the state of the world economy before and after the change in the climate-related parameters. The following subregions and countries are considered in the CGE: North America, South America, Central America, the Caribbean, Guyana and Suriname (considered together), Belize, Europe, Africa, Asia, and Oceania. To obtain more geographical detail for the Caribbean subregion, the results from the CGE module are post-processed to produce approximate values for some macroeconomic variables (changes in real national income in particular) for individual States in the Caribbean aggregate. In the following, the functioning of each module is more specifically described.

\section{Sectoral damage functions}

The first module in ECLAC-CIAM is used to generate exogenous shocks to a number of economic parameters and variables in the core CGE model, on the basis of a given climate scenario. This is done through the application of sectoral "damage functions".

A damage function is a relationship between some variable describing the climate state (in this case, the absolute global surface temperature change from its value in degrees Celsius in the year 2000) and certain parameters of the economic model (usually expressed as a percentage change from the baseline level). The type of sectoral impact determines which parameters are considered. For example, estimated changes in agricultural productivity translate into percentage changes for the multi-factor productivity parameter of "agriculture" in the CGE model. Effects on human health are interpreted as changes in labour endowment or productivity, and so forth.

In figure 2 , for example, three damage functions for the agriculture sector are plotted, corresponding in

FIGURE 1

The modular structure of ECLAC-CIAM

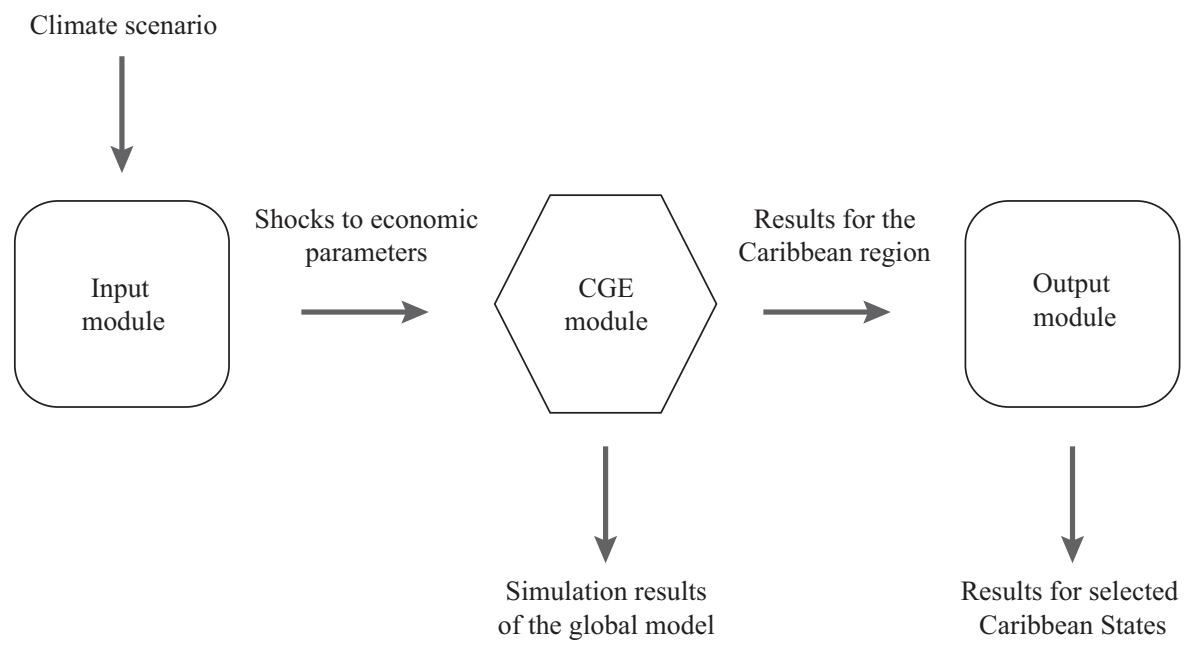

Source: prepared by the author.

CGE: computable general equilibrium. 
FIGURE 2

Latin America and the Caribbean (selected countries and subregions):

five damage functions (agriculture)

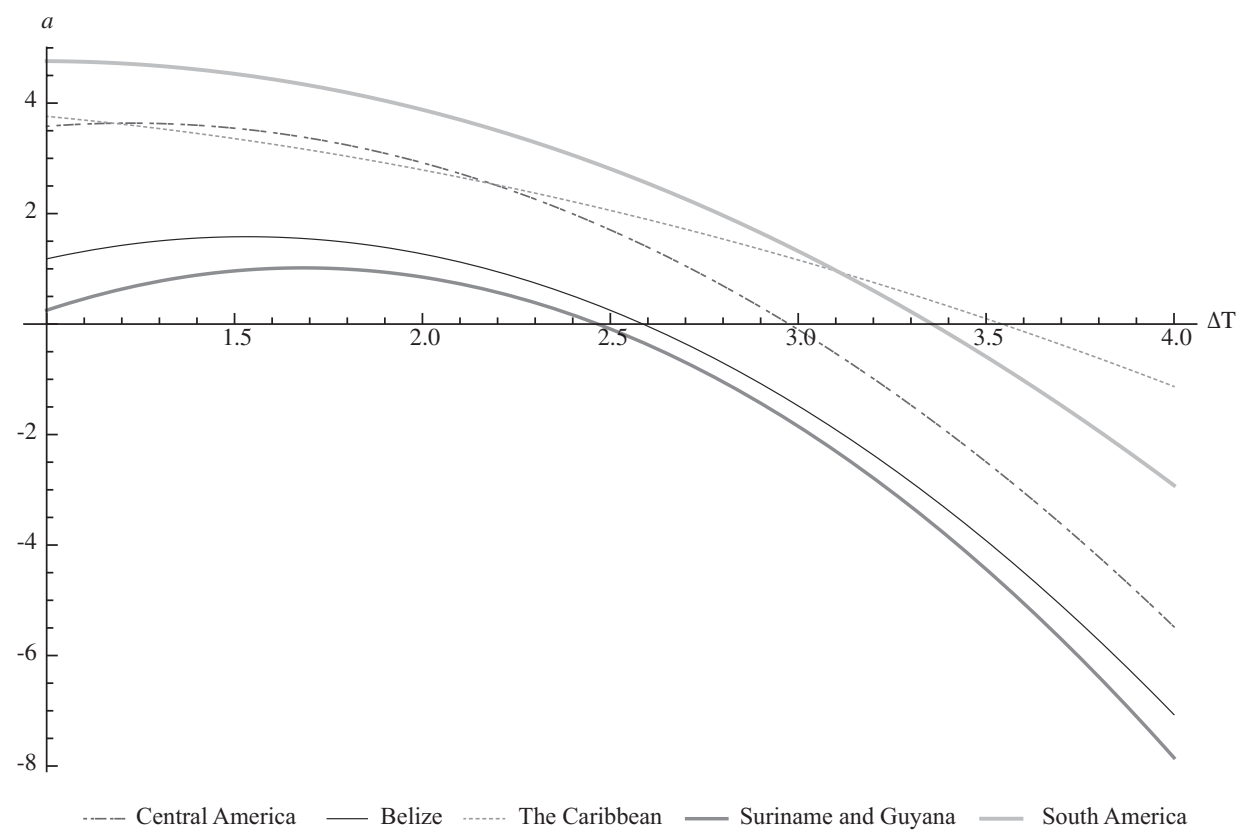

Source: prepared by the author.

the CGE model to the subregions of Central America, the Caribbean and South America, and the countries of Suriname and Guyana (considered together) and Belize.

The horizontal axis measures the change in temperature (in degrees Celsius) from the year 2000. The vertical axis measures the estimated percentage change in total agricultural productivity in the three countries. It should be noted that the estimates refer to the whole agriculture sector, not to a specific crop, and do not consider changes in the water supply or extreme events. The relationship between temperature and productivity in agriculture is a non-linear one: moderate increases in temperature (and in carbon dioxide concentration) are beneficial, higher temperature levels reduce agricultural productivity.

Other damage functions in ECLAC-CIAM are simple linear relationships, often because there is not enough information to estimate the various parameters of nonlinear functions. For example, figure 3 plots the five damage functions for the sea-level-rise effect. In this case, the vertical axis measures the percentage loss in endowments of capital and land stocks in each country.
It is clear that the small island States of the Caribbean are highly vulnerable to sea-level rise.

ECLAC-CIAM considers seven sectoral impacts, and each impact is associated with a specific damage function. In addition to agriculture and sea-level rise, the following impacts are taken into account:

- Water availability. This is a second source of variation for agricultural productivity, which is assumed to depend on estimated changes in runoff. According to current parameter values, an increase of $1^{\circ} \mathrm{C}$ in temperature would reduce agricultural productivity in the Caribbean by $0.21 \%$ because of lower water availability.

- Tourism. Changes in temperature are associated with changes in net receipts from foreign tourists, corresponding to foreign income transfers in the CGE model. A $1^{\circ} \mathrm{C}$ increase in temperature would reduce tourism receipts by US $\$ 8.6$ billion in Central America, US\$ 10 million in Belize, US\$ 5.5 billion in the Caribbean and US\$ 204 million in Suriname and Guyana, but would increase tourism receipts by US\$ 26.8 billion in South America. 
Latin America and the Caribbean (selected countries and subregions): five damage functions (sea-level rise)

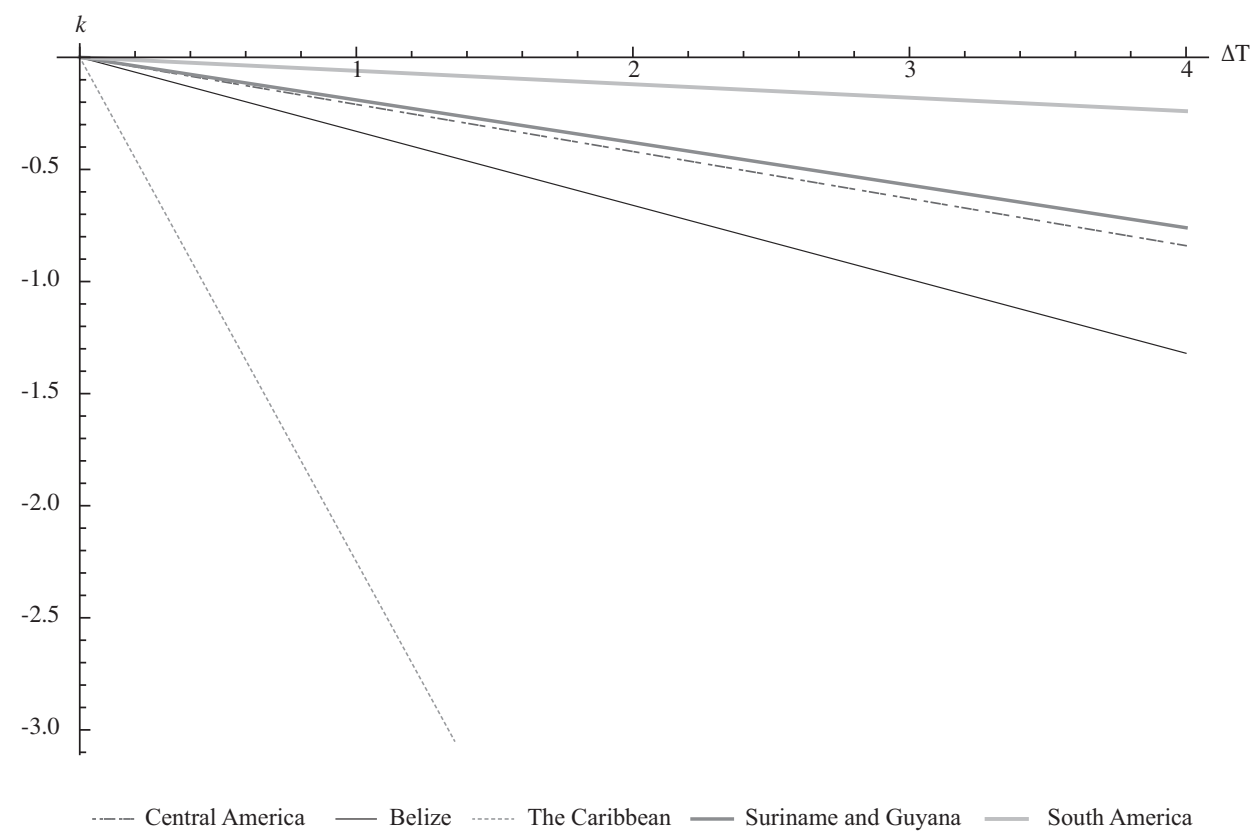

Source: prepared by the author.

- $\quad$ Energy demand. This refers to changes in energy consumption by households, considering both cooling and heating needs. In the CGE model, any variation in energy consumption is accommodated through changes in all other expenses, so that the budget constraint for each household in each country holds. A $1^{\circ} \mathrm{C}$ increase in temperature would increase energy consumption by $0.21 \%$ in Belize and $0.24 \%$ in the Caribbean. It would reduce energy consumption by $0.23 \%$ in Central America, $0.25 \%$ in Suriname and Guyana and $0.02 \%$ in South America.

- Human health: additional cases (mortality and morbidity) of cold-related, heat-related and vector-borne diseases are translated into labour productivity changes in each region. $\mathrm{A} 1^{\circ} \mathrm{C}$ increase in temperature would reduce labour productivity by $0.58 \%$ in Central America, $0.57 \%$ in Belize, $0.13 \%$ in the Caribbean and $0.11 \%$ in Suriname and Guyana and the rest of South America.

- On-the-job productivity: this refers to labour productivity in open-air activities, which may be directly dependent on temperature and humidity. A $1{ }^{\circ} \mathrm{C}$ increase in temperature would reduce (average) labour productivity by $0.43 \%$ in all five regions, except South America, where it would fall by $0.38 \%$.
All figures are indicative and should be treated with caution. The parameters of the damage functions can be changed whenever more reliable information becomes available. At present, parameter values are estimated on the basis of a wide range of sectoral studies, and correspond to values used in the ENVISAGE integrated assessment model (Roson and Van der Mensbrugghe, 2012) developed at the World Bank.

Most of the sectoral studies used for this purpose make no explicit reference to the Caribbean or other tropical regions. For example, the parameters of the damage functions for agricultural productivity (figure 2) are obtained by weighted averaging of some crop response functions. Three crops have been considered: wheat, rice and maize. Although these are the three most widely grown crops in the world, they are certainly not representative of tropical agriculture. It is hoped that better data and more reliable parameter estimates will be made available in future versions of ECLAC-CIAM.

\section{The core CGE model}

The core of ECLAC-CIAM is a standard GTAP computable general equilibrium (CGE) model. This is a large macroeconomic model that includes thousands of 
equations grouped into 213 categories. A complete formal description of the model is beyond the scope of this paper, but it can be easily found in Hertel and Tsigas (1997). The CGE model, which is not specifically designed for climate change analysis, provides a representation of the world economy and its interdependencies across regions, industries and markets.

Most parameters in the CGE model are calibrated. This means that their values are set in such a way that the model baseline replicates observed statistical data, such as consumption levels and trade patterns. Simulation exercises are performed by varying exogenous variables (e.g., tax rates, productivity factors and factor endowments) and by computing a counterfactual general equilibrium for the world economy in which product and primary factor markets alike invariably balance each other out. Therefore, a CGE model is primarily designed to study structural adjustment processes triggered by changes in some parameters rather than to forecast future economic scenarios.

Production in each regional industry is carried out by employing intermediate and primary factors. Intermediate factors are produced by other industries, domestic or foreign. The role of each factor in the production process is determined when the model is calibrated, i.e., when parameter values are set in accordance with observed industrial cost structures. Demand for production factors may change in simulation exercises because of variations in production levels and relative prices. Expensive factors are (partially) substituted by less expensive ones, on the basis of the assumed industrial production functions and "elasticity of substitution" parameters (determining how sensitive factor patterns may be to relative prices).

Because regional industries are large heterogeneous aggregates, goods produced in the same industry but in different regions are treated as distinct goods. Intermediate and final demand for any product is split within a nesting structure: first, relative prices determine how much is imported and how high domestic demand is; second, imports are allocated between different foreign sources, again on the basis of relative prices and elasticities of substitution (which may vary by region and sector). The prices of imported goods include international transport and trade margins, tariffs and non-tariff trade barriers.

In equilibrium, production volumes in each regional industry must match total demand, encompassing intermediate demand from other domestic and foreign industries, domestic and foreign household consumption, public expenditure, and domestic and foreign demand for (physical) investment. Equilibrium conditions are achieved by setting appropriate product and primary factor prices.

Primary resource endowments are normally given, although it is possible to change the partition between endogenous and exogenous variables in the model. Primary factors are internationally immobile but fully or partially mobile between industries in the domestic economy. In equilibrium, factor endowments must match the demand generated by the various domestic industries.

National income is the value of all domestically owned primary resources. This includes wages, capital returns, land and resource rents, and tax revenue. National income is allocated between private household consumption, public expenditure and savings. Consumption patterns are determined on the basis of utility function maximization subject to a budget constraint. Therefore, final consumption demand is sensitive to relative prices.

Regional savings are hypothetically pooled by a virtual international bank, which then distributes them to regional investments on the basis of expected future returns (linked to current returns). Therefore, regional savings and investments do not necessarily match. National accounting identities imply that any excess saving mirrors a foreign trade surplus, and vice versa. However, equilibrium conditions require the balance of payments, possibly including foreign transfers and remittances, to be zero. This condition is satisfied by adjusting international exchange rates.

When the model is calibrated, parameter values are set so that it endogenously computes production, consumption and investment levels in a way that is fully consistent with national accounts statistics. Counterfactual equilibria are obtained by changing the calibration values for exogenous parameters and variables.

This is exactly what happens when a simulation exercise is run with ECLAC-CIAM. Climate change damage functions are first used to estimate how variations in climate conditions (changes in the average surface temperature) affect a number of exogenous variables in the CGE model, such as labour productivity, total agricultural productivity, land and capital endowments, and so on. All changes in exogenous variables are simultaneously inserted into the CGE model, which is then used to compute consistent levels for variables such as relative prices, income and utility levels, investments, international trade patterns, production volumes, tax revenues, and so on. This rich array of results provides a global picture of the economic consequences of climate change. 


\section{Downscaling}

Although the output of a CGE simulation may be quite sizeable, it may not provide results at the desired level of detail in some circumstances. For example, it would be interesting to know the effects of climate change on individual States within the Caribbean aggregate region. This is not directly possible, because calibration of the CGE model requires very detailed national accounting data, which are not available for individual States in the Caribbean.

Nonetheless, some results may be indirectly obtained through the application of microsimulation techniques. In ECLAC-CIAM, microsimulation techniques are used to obtain indirect estimates of changes in real income, i.e., gross domestic product (GDP), for the following small island States of the Caribbean that have been selected for analysis:

- Antigua and Barbuda

- Barbados

- Bermuda

- Caribbean small island States

- Cuba

- Dominica

- Dominican Republic

- Grenada

- Jamaica

- $\quad$ Saint Kitts and Nevis

- Saint Lucia

- $\quad$ Saint Vincent and the Grenadines

- Trinidad and Tobago

This is made possible by the fact that GDP is just the sum of the value added produced by all industries in a country. The CGE model provides, in addition to estimates of GDP (real and nominal) for all subregions in the set, estimates of changes in industrial value added for all subregions, including the Caribbean. From the World Development Indicators (WDI) database of the World Bank, meanwhile, it is possible to obtain the sectoral composition of national income for all the above countries and for the six industries of the CGE model. A reasonable approximation to the change in national income can therefore be obtained by calculating a weighted average of changes in industrial value added, where the weights are given by sectoral shares of national GDP. This operation is performed by the output module of ECLAC-CIAM.

\section{Data requirements}

Deployment of ECLAC-CIAM requires data to implement the CGE model, together with information to estimate parameters for the damage functions and to conduct the post-processing analysis. Parameters for damage functions have been obtained from a number of different studies covering various climate change impacts. The downscaling procedure is based on data for the value added composition of national GDP in the Caribbean States.

Many of the parameters of the core CGE models are calibrated, although elasticities of substitution are an exception, as they are taken from the literature or from conventional reference values. Calibrating a CGE model entails a choice of parameter values such that the model endogenously computes trade flows, consumption and production volumes that are fully consistent with available input-output or social accounting matrices. The calibration process may be long and cumbersome (and dependent on data availability), but global, standardized data resources are now available, which makes matters much easier. ECLAC-CIAM has been calibrated using the GTAP 8 Data Base.

Since 1992, the Global Trade Analysis Project (GTAP) consortium, headed by Purdue University in the United States, has been collecting national accounts with a view to building and maintaining a global social accounting matrix (SAM) database. The GTAP 8 Data Base is the eighth major public release of the GTAP Data Base since the project began. A GTAP Data Base is created on the basis of domestic databases or input-output (I-O) tables, which are combined with international datasets on macroeconomic aggregates, bilateral trade, energy, agricultural input-output and trade protection for the new reference years. Interim releases of the database are constructed as significant updated datasets become available. Improvements are also made in data sourcing, scope and construction procedures. In GTAP 8 , the data come from a variety of sources, including the World Bank, national statistical agencies, the International Trade Centre (ITC)/Centre for International Prospective Studies and Information (CEPII), the United Nations Commodity Trade Statistics Database (COMTRADE), the International Energy Agency (IEA), the Organization for International Co-operation and Development (OECD) and many others, and are reconciled within a consistent framework. The whole process of construction is quite complex and is fully documented at www.gtap.org. 


\section{IV}

\section{An illustrative simulation exercise}

To illustrate how ECLAC-CIAM works and what kind of results it can produce, this section presents an example of a simulation exercise. ${ }^{1}$ Let us consider IPCC SRES scenario A2 for the year 2050, which involves an average temperature increase of $1.2^{\circ} \mathrm{C}$ relative to the year 2000 . The damage functions express this scenario in terms of changes in economic variables, namely:

- An increase in land productivity of $3.38 \%$ in Central America, $1.03 \%$ in Belize, $0.68 \%$ in the Caribbean, $0.41 \%$ in Suriname and Guyana and $4.64 \%$ in South America.

- A decrease in capital stock of $0.25 \%$ in Central America, $0.40 \%$ in Belize, $2.69 \%$ in the Caribbean, $0.22 \%$ in Suriname and Guyana and $0.08 \%$ in South America.

- A decrease in labour productivity of $1.10 \%$ in Central America, $1.20 \%$ in Belize, $0.67 \%$ in the

1 This exercise can be easily replicated by interested readers.
Caribbean, $0.64 \%$ in Suriname and Guyana and $0.58 \%$ in South America.

- A decrease in demand for tourism services of $1.38 \%$ in Central America, $1.43 \%$ in Belize, $3.34 \%$ in the Caribbean and $7.52 \%$ in Suriname and Guyana, and an increase of $2.22 \%$ in South America.

- A decrease in energy production of $0.05 \%$ in Belize, Suriname and Guyana, $0.06 \%$ in the Caribbean and Central America and $0.04 \%$ in South America.

These (like the corresponding values for all other regions) constitute exogenous shocks for the general equilibrium model. Once the CGE model has been run, estimates for several economic variables become available. For example, table 1 reports the estimated changes in production volumes in the agriculture, energy, light manufacturing, heavy manufacturing, market services and non-market services sectors in three subregions and three countries of Latin America and the Caribbean (results are available for all regions and industries in the model, however).

TABLE 1

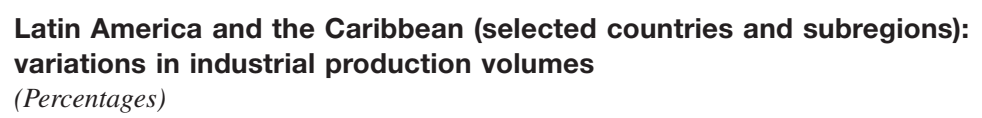

Latin America and the Caribbean (selected countries and subregions): variations in industrial production volumes (Percentages)

\begin{tabular}{lccccc}
\hline & Central America & Belize & The Caribbean & Suriname and Guyana & South America \\
\hline Agriculture & -0.13 & -1.83 & 0.39 & -0.6 & -1.84 \\
Energy & 1.21 & 0.09 & 4.1 & 0.79 & -2.75 \\
Light manufacturing & 0.61 & 0.26 & 2.0 & 3.29 & -1.24 \\
Heavy manufacturing & 1.72 & -0.27 & 3.71 & 6.57 & -2.51 \\
Market services & -1.64 & -1.38 & -4.22 & -7.33 & 1.67 \\
Non-market services & -0.95 & -1.1 & -1.82 & -0.99 & -0.69 \\
\hline
\end{tabular}

Source: prepared by the author.

It should be noted that the exogenous change in land productivity does not match the estimated change in agricultural production by volume. A similar reasoning applies to energy production and market services. This is because the model accounts for changes in relative competitiveness and in the terms of trade. In the Caribbean, for example, falling demand for market services (a consequence of the reduced attractiveness of Caribbean tourist destinations) leads to lower production volumes in agriculture (a supplier to the tourism industry). It also implies a real devaluation of the local currency, lowering production costs and fostering international competitiveness in the energy and manufacturing sectors.

Table 2 shows percentage changes in household consumption levels by industry. Lower consumption levels indicate reduced well-being. Changes in relative prices also result in shifting consumption patterns.

Simulation results show that climate change effects might bring about a quite sizable reduction in consumption levels, especially in the Caribbean. ECLAC-CIAM can also provide a more detailed welfare analysis, for instance by 
Latin America and the Caribbean (selected countries and subregions): variations in household consumption volumes

(Percentages)

\begin{tabular}{|c|c|c|c|c|c|}
\hline & Central America & Belize & The Caribbean & Suriname and Guyana & South America \\
\hline Agriculture & 0.21 & -0.23 & -1.1 & -0.64 & 0.6 \\
\hline Energy & -0.87 & -1.55 & -4.12 & -1.95 & 0.17 \\
\hline Light manufacturing & -0.38 & -1.16 & -2.55 & -1.29 & 0.22 \\
\hline Heavy manufacturing & -0.89 & -1.8 & -4.13 & -2.16 & -0.05 \\
\hline Market services & -0.72 & -1.71 & -3.37 & -1.91 & -0.26 \\
\hline Non-market services & -0.86 & -1.91 & -3.05 & -1.77 & -0.35 \\
\hline
\end{tabular}

Source: prepared by the author.

computing the "equivalent variation" (Ev) for each region, which is a money-metric index of welfare impacts. The $\mathrm{EV}$ is the change in income that would have produced the same variation in utility levels, at constant prices. The finding is that climate change by the year 2050 will generate economic consequences equivalent to a loss of about US\$ 7.5 billion a year in Central America. EV losses for the other subregions and reference countries are: US\$ 17 million in Belize, US\$ 6.7 billion in the Caribbean, US\$ 84 million in Suriname and Guyana and US\$ 4.2 billion in South America.

Clearly, the magnitude of the loss depends on the size of the regional economy. To better appreciate the effects on welfare, table 3 displays the EV relative to national income, which amounts to the percentage change in real GDP. In addition to results for the aggregate subregions and countries, we present the estimated variation for individual countries within the Caribbean, obtained from the output module of ECLAC-CIAM, as well as other estimates, whose meaning is explained in what follows.

The "Overall" column shows the estimated change in regional GDP. We can see that the impact on Caribbean GDP is quite large: by 2050, because of climate change, national income is forecast to be about $3 \%$ lower than its hypothetical level in the absence of climate change. The corresponding results for Belize, Guyana and Suriname are also quite significant, whereas the impact on Central and South America is significantly smaller.

The "Upper" and "Lower" columns refer to a sensitivity analysis on the simulation results. In this example, we informed the model software that

Latin America and the Caribbean (selected countries and subregions): variations in real national income

(Percentages)

\begin{tabular}{|c|c|c|c|c|c|c|c|}
\hline & Overall & Lower & Upper & Land & Labour & Capital & Tourism \\
\hline Central America & -0.73 & -0.84 & -0.63 & 0.03 & -0.43 & -0.18 & -0.16 \\
\hline Belize & -1.46 & -1.69 & -1.24 & -0.33 & -0.75 & -0.17 & -0.22 \\
\hline The Caribbean & -2.92 & -3.47 & -2.37 & 0.04 & -0.43 & -1.49 & -1.05 \\
\hline Antigua and Barbuda & -3.20 & -3.72 & -2.74 & -0.09 & -0.43 & -1.51 & -1.24 \\
\hline Barbados & -3.11 & -3.64 & -2.61 & -0.06 & -0.43 & -1.50 & -1.18 \\
\hline Bermuda & -3.76 & -4.17 & -3.51 & -0.11 & -0.46 & -1.54 & -1.55 \\
\hline Caribbean small island States & -2.71 & -3.31 & -2.06 & -0.03 & -0.42 & -1.48 & -0.96 \\
\hline Cuba & -3.22 & -3.71 & -2.77 & 0.03 & -0.44 & -1.51 & -1.21 \\
\hline Dominica & -3.20 & -3.67 & -2.80 & 0.25 & -0.45 & -1.50 & -1.13 \\
\hline Dominican Republic & -2.68 & -3.28 & -2.04 & 0.05 & -0.42 & -1.48 & -0.92 \\
\hline Grenada & -3.15 & -3.66 & -2.67 & -0.02 & -0.43 & -1.51 & -1.19 \\
\hline Jamaica & -2.97 & -3.52 & -2.43 & 0.01 & -0.43 & -1.49 & -1.09 \\
\hline Saint Kitts and Nevis & -3.17 & -3.69 & -2.68 & -0.10 & -0.43 & -1.51 & -1.23 \\
\hline Saint Lucia & -3.29 & -3.78 & -2.87 & -0.04 & -0.44 & -1.51 & -1.27 \\
\hline Saint Vincent and the Grenadines & -3.14 & -3.65 & -2.67 & 0.05 & -0.44 & -1.50 & -1.16 \\
\hline Suriname and Guyana & -1.66 & -2.05 & -1.27 & -0.08 & -0.40 & -0.12 & -1.06 \\
\hline South America & -0.19 & -0.30 & -0.08 & -0.01 & -0.36 & -0.04 & 0.22 \\
\hline
\end{tabular}

Source: prepared by the author. 
uncertainty existed about the correct values for some shocked parameters. More specifically, we assumed that changes in labour productivity and demand for market services could take any value in the range $+/-50 \%$ of the baseline estimate. In other words, we replaced a single value for the variation in specific parameters with a (rectangular) probability distribution. The model could then infer the probability distribution of output variables associated with the distribution of input shocks. This was obtained by running the simulation several times with alternative input values, using Stroud's statistical quadrature technique (Stroud, 1957; DeVuyst and Preckel, 1997). Consequently, information is produced not only about central values for all output variables, but also about other statistical moments, like the standard deviation. In table 3, the "Lower" column shows the estimated change in real GDP minus its estimated standard variation, whereas in the "Upper" column the standard variation is added.

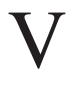

\section{Conclusions}

ECLAC-CIAM is a modelling platform which has been produced to assess the economic consequences of climate change in the Caribbean. The model is aimed at filling a knowledge gap by making it possible to produce a quantitative assessment of the economic effects of climate change.

It is clear that the model can be improved in several different ways: better quality of economic data, more reliable estimates of the direct physical effects of climate change, improved climate scenarios, finer industrial and regional disaggregation, etc.

Nonetheless, the current version of ECLAC-CIAM, which can be freely accessed, downloaded and even modified, is already a fully working, state-of-the-art model. As such, it can be readily used to conduct simulation exercises like the one presented in this paper. From this simple illustrative simulation, a number of key findings can be obtained. Our results confirm that the Caribbean is a highly vulnerable region in which climate change is expected to generate sizeable and negative economic consequences. Sea-level rise, bringing
Therefore, the two values represent the bounds of a likelihood interval for the estimated change in regional GDP.

The remaining four columns on the right present results for some other simulation exercises in which only one class of climate change effects is taken into account at a time. In the "Labour" column, for example, estimates of variations in real GDP are obtained by varying only labour productivity parameters, while keeping all other parameters (e.g., land productivity) unchanged. In this way, it is possible to single out the contribution of a specific climate change effect to the overall result. We can see that variations in labour productivity are indeed the most important economic effect of climate change in Belize and Central and South America. Losses of capital stock associated with sea-level rise are the most important impact in the Caribbean, whereas a drop in tourism demand is the most important factor in Suriname and Guyana.

about losses of land and capital infrastructure stocks, and a decline in the tourism industry are the two most significant factors. These results can inform mitigation and adaptation policies at both the regional and the international level.

The model is very flexible and other simulation exercises could easily be designed, with changes to the time horizon, climate scenario or sectoral impacts, for example. All other exogenous parameters in the CGE model can be modified as well, which is especially helpful when it comes to exploring the interactions between climate and other policies (e.g., fiscal reforms, trade liberalization, productivity growth).

It is also possible to "swap" endogenous and exogenous variables in the model. For example, in the standard closure the model computes equilibrium wages to ensure full employment of the given labour stock. If, instead, (actual) wages are specified ex ante, labour demand may become endogenous. The difference between the total labour supply and estimated demand is readily interpreted as involuntary unemployment. 


\section{Bibliography}

Anthoff, D. and R.S.J. Tol (2008), “The impact of climate change on the balanced-growth-equivalent", Papers, No. 228, Dublin, Economic and Social Research Institute.

Atkinson, G. and others (2010), "Trade in 'virtual carbon': empirical results and implications for policy", Policy Research Working Paper Series, No. 5194, Washington, D.C., World Bank.

Bernard, A. and M. Vielle (2008), "GEMINI-E3, a general equilibrium model of international-national interactions between economy, energy and the environment", Computational Management Science, vol. 5, No. 3, Springer.

Bosetti, V. and others (2006), "WITCH: a world induced technical change hybrid model", The Energy Journal, vol. 27, Cleveland, International Association for Energy Economics.

Burniaux, J.-M., G.. Nicoletti and J. Oliveira Martins (1992), "GREEN: a global model for quantifying the costs of policies to curb $\mathrm{CO}_{2}$ emissions", OECD Economic Studies, No. 19, Paris, Organization for Economic Cooperation and Development (OECD).

Burniaux, J.-M. and T.P. Truong (2002), "GTAP-E: An energyenvironmental version of the GTAP model", GTAP Technical Paper, No. 16, West Lafayette, Indiana.

DeVuyst, E.A. and P.V. Preckel (1997), "Sensitivity analysis revisited: a quadrature-based approach", Journal of Policy Modelling, vol. 19, No. 2, Amsterdam, Elsevier.

Eboli, F., R. Parrado and R. Roson (2010), "Climate change feedback on economic growth: explorations with a dynamic general equilibrium model", Environment and Development Economics, vol. 15, No. 5, Cambridge, Cambridge University Press.

ECLAC (Economic Commission for Latin America and the Caribbean) (2011), "The Economics of Climate Change in the Caribbean: Summary Report 2011" (LC/CAR/L.299), Port of Spain, ECLAC subregional headquarters for the Caribbean, September.

Hertel, T.W. and M.E. Tsigas (1997), "Structure of GTAP", Global Trade Analysis: Modeling and Applications, T.W. Hertel (ed.), Cambridge, Cambridge University Press.

Hope, C., J. Anderson and P. Wenman (1993), "Policy analysis of the greenhouse effect: an application of the PAGE model", Energy Policy, vol. 21, No. 3, Amsterdam, Elsevier.

IPCC (Intergovernmental Panel on Climate Change) (2000), IPCC Special Report Emissions Scenarios, Geneva.

Jensen, J. and M.H. Thelle (2001), "What are the gains from a multigas strategy?", FEEM Working Paper, No. 84, Milan, Fondazione Eni Enrico Mattei.
Kemfert, C. (2002), "An integrated assessment model of economyenergy-climate - The model WIAGEM", Integrated Assessment, vol. 3, No. 4, Routledge.

Lee, H., D. van der Mensbrugghe and J. Oliveira Martins (1994), "The OECD GREEN model: an updated overview", OECD Development Centre Working Papers, No. 97, Paris, OECD Publishing.

Manne, A.S., M. Mendelsohn and R. Richels (1995), "MERGE A model for evaluating regional and global effects of GHG reduction policies", Energy Policy, vol. 23, No. 1, Amsterdam, Elsevier.

Nordhaus, W.D. (1994), Managing the Global Commons: The Economics of Climate Change, Cambridge, Massachusetts, The MIT Press.

Nordhaus, W.D. and Z. Yang (1996), "A regional dynamic generalequilibrium model of alternative climate-change strategies", American Economic Review, vol. 86, No. 4, Nashville, Tennessee, American Economic Association.

Paltsev, S. and others (2005), "The MIT emissions prediction and policy analysis (EPPA) model: version 4", Report, No. 125, Cambridge, Massachusetts, MIT Joint Program on the Science and Policy of Global Change.

Pant, H. (2007), "GTEM: Global Trade and Environment Model", Technical Report, Canberra, Australian Bureau of Agricultural and Resource Economics and Sciences (ABARES).

Popp, D. (2003), "ENTICE: endogenous technological change in the DICE model of global warming", NBER Working Paper, No. 9762, Cambridge, Massachusetts, National Bureau of Economic Research.

Roson, R. and D. van der Mensbrugghe (2012), "Climate change and economic growth: impacts and interactions", International Journal of Sustainable Economy, vol. 4, No. 3, Inderscience Enterprises Ltd.

Springer, K. (1998), "The DART general equilibrium model: a technical description”, Kiel Working Papers, No. 883, Kiel, Kiel Institute for the World Economy.

Stern, N. (2007), The Economics of Climate Change: The Stern Review, Cambridge, Cambridge University Press.

Stroud, A.H. (1957), "Remarks on the disposition of points in numerical integration formulas", Mathematical Tables and Other Aids to Computation, vol. 11, No. 60, Providence, American Mathematical Society. 